\title{
Pharmacokinetics of Isocorynoxeine in Rat Plasma after Intraperitoneal Administration by UPLC-MS/MS
}

\author{
Haichao $\mathrm{Zhan}^{1} \dagger$, Zhen $\mathrm{Wei}^{2} \dagger$, Ke Ren ${ }^{3}$, Shuhua Tong ${ }^{1}$, Xianqin $\mathrm{Wang}^{4 *}$ and Qing $\mathrm{Wu}^{\mathbf{2}^{*}}$ \\ ${ }^{\prime}$ Department of Clinical Pharmacy, Jinhua Central Hospital, Jinhua 321000, China \\ The First Affiliated Hospital of Wenzhou Medical University, Wenzhou 325035, China \\ ${ }^{3}$ Department of Pharmacy, Ningbo YinZhou No.2 Hospital, Ningbo 315192, China \\ ${ }^{4}$ Analytical and testing Centre, School of Pharmaceutical Sciences, Wenzhou Medical University, Wenzhou 325035, China
}

Received: 27 Sep 2019; accepted: 12 Nov 2019

\begin{abstract}
Isocorynoxeine is one of the main alkaloids in Chinese medicinal herbs, and has pharmacological activities such as antihypertensive, sedative, anticonvulsant, and neuronal protection. It is an effective component of Uncaria for the treatment of hypertension. In this study, we used a fast and sensitive ultra-performance liquid chromatographytandem mass spectrometry (UPLC-MS/MS) to detect isocorynoxeine in rat plasma and investigated its pharmacokinetics in rats. Six rats were given isocorynoxeine $(15 \mathrm{mg} / \mathrm{kg})$ by intraperitoneal (i.p.) administration. Blood $(100 \mu \mathrm{L})$ was withdrawn from the caudal vein at 5 and $30 \mathrm{~min}$ and $1,2,4,6,8,12$, and $24 \mathrm{~h}$ after administration. Chromatographic separation was achieved using a UPLC BEH C18 column using a mobile phase of acetonitrile$0.1 \%$ formic acid with gradient elution. Electrospray ionization (ESI) tandem mass spectrometry in the multiple reaction monitoring (MRM) mode with positive ionization was applied. Intra-day and inter-day precisions (relative standard deviation, \%RSD) of isocorynoxeine in rat plasma were lower than $12 \%$. The method was successfully applied in the pharmacokinetics of isocorynoxeine in rats after intraperitoneal administration. The $t_{1 / 2}$ of isocorynoxeine is $4.9 \pm 2.1 \mathrm{~h}$, which indicates quick elimination.
\end{abstract}

Keywords: isocorynoxeine, pharmacokinetics, rat, UPLC-MS/MS

\section{Introduction}

Uncaria rhynchophylla is a plant of the family Rubiaceae, which grows in valleys and streams [1-3]. It is widely distributed in the southern provinces of China $[4,5]$. It is used in traditional Chinese medicine for headache, dizziness, cold, convulsions, convulsions, and pregnancy [6-10], as well as in treatment of conditions such as eclampsia and hypertension. Alkaloids are the main medicinal ingredients of $U$. rhynchophylla, and the changes and distribution characteristics of medicinal ingredients in the body are closely related to their pharmacological effects [11-15]. Isocorynoxeine is one of the main tetracyclic oxindole alkaloids found in U. rhynchophylla and has pharmacodynamic effects, such as antihypertensive, sedative, hypnotic, and anti-age dementia, showing a certain development value [16-18]. Although the pharmacokinetic characteristics of isocorynoxeine given by oral administration in rat had been revealed in recent years, no study on the i.p. administration in vivo until now has been investigated [18, 19]. In order to further understand the absorption and distribution of isocorynoxeine by i.p. administration in vivo, it is necessary to carry out systematic research on pharmacokinetic characteristics to provide a theoretical basis for drug development. Therefore, a validated method for determination of isocorynoxeine was needed for analysis and drug exploration in the future.

There have been several LC-MS methods reported for the determination of isocorynoxeine in rat plasma [20, 21]. Cai

\footnotetext{
* Author for correspondence: lankywang@163.com (X. Wang), 13588922312@163.com (Q.Wu).

$\dagger$ These authors contributed equal to this work.
}

et al. developed a liquid chromatography-mass spectrometry (LC-MS) method for the determination of isocorynoxeine in rat plasma with an LLOQ of $5 \mathrm{ng} / \mathrm{mL}$; it needed $10 \mathrm{~min}$ for the runtime, and sample preparation was performed by using liquid-liquid extraction with ethyl acetate [21]. Wang et al. presented the pharmacokinetics and mass balance of isocorynoxeine in rats after an oral dose of $40.0 \mathrm{mg} / \mathrm{kg}$ and an intravenous dose of $4.0 \mathrm{mg} / \mathrm{kg}$ through detection of isocorynoxeine and its in vivo metabolites, using an optimized LC-MS [20]; it needed $20 \mathrm{~min}$ for the runtime, and tedious plasma samples preparation was used. However, these methods needed too long runtime, and the selective ion monitoring (SIM) mode was used to quantify isocorynoxeine in rat plasma in their study.

In this study, we presented a fast and sensitive UPLC-MS/ MS method for isocorynoxeine in rat plasma in the multiple reaction monitoring (MRM) mode with an LLOQ of $1 \mathrm{ng} / \mathrm{mL}$ and investigated its pharmacokinetics in rats, using a simple and fast one-step acetonitrile precipitation method to process the plasma samples, which only needed $50 \mu \mathrm{L}$ rat plasma and 3 min for the runtime.

\section{Materials and Methods}

Chemicals and Animals. Isocorynoxeine (purity $>98 \%$, Figure 1) was purchased from Chengdu Mansite BioTechnology Co., Ltd. (Chengdu, China). HPLC-grade methanol and formic acid were purchased from Merck (Darmstadt, Germany). Ultrapure water was prepared using a Millipore Milli-Q water system (Bedford, MA, USA). Sprague Dawley (SD) rats (male, body weight 200-220 g) were

This is an open-access article distributed under the terms of the Creative Commons Attribution-NonCommercial 4.0 International License (https://creativecommons.org/licenses/by-nc/4.0/), which permits unrestricted use, distribution, and reproduction in any medium for non-commercial purposes, provided the original author and source are credited, a link to the CC License is provided, and changes - if any - are indicated. 


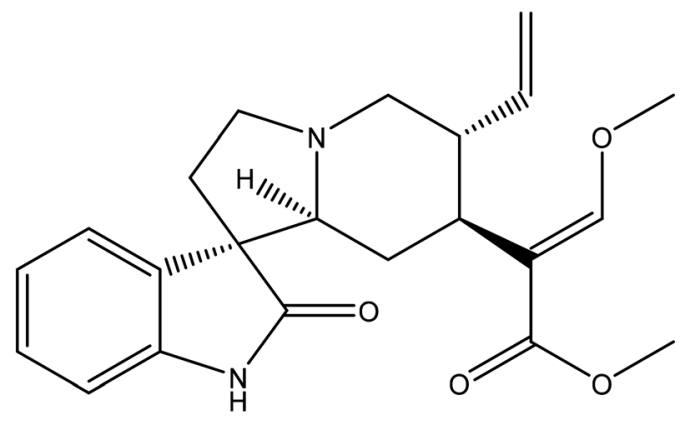

(A)

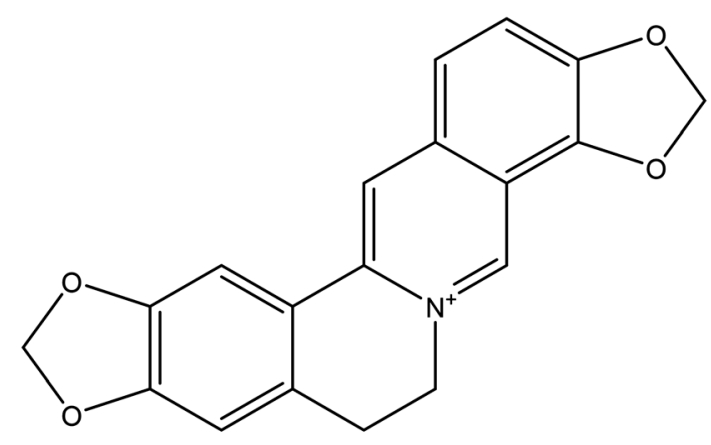

(B)

Figure 1. Chemical structure of isocorynoxeine (A) and the IS (B)

obtained from the Animal Experimental Center of Wenzhou Medical University.

Instruments and Conditions. An ACQUITY H-Class UPLC and a XEVO TQS-micro triple quadrupole mass spectrometer (Waters Corp, Milford, MA, USA) were used in this study. A UPLC BEH C18 $(2.1 \mathrm{~mm} \times 50 \mathrm{~mm}, 1.7 \mu \mathrm{m})$ was used at $40{ }^{\circ} \mathrm{C}$. The mobile phase was composed of acetonitrile and $0.1 \%$ formic acid in gradient elution, and the flow rate was set at $0.5 \mathrm{~mL} / \mathrm{min}$. The gradient elution was as follows: $0-0.2 \mathrm{~min}$, acetonitrile $10 \% ; 0.2-1.0 \mathrm{~min}$, linear acetonitrile from $10 \%$ to $80 \%$; $1.0-2.0 \mathrm{~min}$, acetonitrile $80 \%$; $2.0-2.1 \mathrm{~min}$, linear acetonitrile from $80 \%$ to $10 \%$; and $2.1-$ $3.5 \mathrm{~min}$, acetonitrile $10 \%$.

Nitrogen was used as the desolvation gas $(800 \mathrm{~L} / \mathrm{h})$ and nebulizing gas. The capillary voltage was set at $2.2 \mathrm{kV}$, the ion source temperature was $150{ }^{\circ} \mathrm{C}$, and the desolvation temperature was $400{ }^{\circ} \mathrm{C}$. ESI in the MRM mode with positive ionization was used: $383.2 \rightarrow 159.9$ for isocorynoxeine, $\mathrm{m} / \mathrm{z}$ $320.2 \rightarrow 292.0$ for the internal standard (IS).

Plasma Processing. In a $1.5-\mathrm{mL}$ centrifuge tube, $50 \mu \mathrm{L}$ plasma was added, further diluted with $200 \mu \mathrm{L}$ acetonitrile (containing the IS of $50 \mathrm{ng} / \mathrm{mL}$ ), mixed by a vortexer for $1.0 \mathrm{~min}$, and centrifuged at $13,000 \mathrm{rpm}$ for $10 \mathrm{~min}$ at $4{ }^{\circ} \mathrm{C}$. The supernate $(100 \mu \mathrm{L})$ was transferred into a liner pipe in vial, and injection volume was set at $1 \mu \mathrm{L}$.

Method Validation. The validation method was established in accordance with the guidance of the US Food and Drug Administration (FDA) [22, 23].

To explore whether endogenous substance would interfere with the detection of the compound and the internal standard, blank rat plasma samples from 6 different sources and the LLOQ samples prepared with the corresponding blank rat plasma were detected by UPLC-MS/MS. The detected concentration of LLOQ should be the baseline value of blank plasma plus concentration of added isocorynoxeine, and the deviation should be within $\pm 20 \%$.

Eight detected concentrations $(1-2000 \mathrm{ng} / \mathrm{mL})$ were used as the $x$-axis, and the peak area ratio of the sample to the internal standard was used as the $y$-axis. A standard curve (linear regression equation) was obtained using the weighted leastsquares method $\left(W=1 / x^{2}\right)$.

QC samples at low, medium, and high concentrations (50, 900 , and $1800 \mathrm{ng} / \mathrm{mL}$ ) were detected 6 times within 3 days. Intra- and inter-day precisions and accuracy were calculated according to the concentrations of the QC samples calculated by the intra-day standard curve.

Recovery was assessed by the comparison of peak areas between QC samples (at 3 concentrations) and standard samples. By spiking standard solutions into the processed blank plasma, 3 solutions with low, medium, and high concentrations (50, 900 , and $1800 \mathrm{ng} / \mathrm{mL}$ ) were prepared. The matrix effect was evaluated by comparing between detected peak areas of the 3 solutions and those of standard solutions $(50,900$, and $1800 \mathrm{ng} /$ $\mathrm{mL})$ diluted with acetonitrile- $0.1 \%$ formic acid $(1: 1, v / v)$.

Stability of isocorynoxeine was detected in the plasma samples that were placed at room temperature for $6 \mathrm{~h}$, processed by protein precipitation and placed at room temperature for $24 \mathrm{~h}$, frozen-thawed for 3 times, and placed at $-70^{\circ} \mathrm{C}$ for 30 days.

Pharmacokinetics. Six rats were given isocorynoxeine $(15 \mathrm{mg} / \mathrm{kg}$ ) by intraperitoneal (i.p.) administration. The blood $(100 \mu \mathrm{L})$ was withdrawn from the caudal vein at 5 and $30 \mathrm{~min}$ and 1, 2, 4, 6, 8, 12, and $24 \mathrm{~h}$ after administration and collected into $1.5-\mathrm{mL}$ centrifuge tubes containing heparin. Plasma $(50 \mu \mathrm{L})$ was collected after centrifuging at $3000 \mathrm{rpm}$ for $10 \mathrm{~min}$ and stored at $-20{ }^{\circ} \mathrm{C}$. Pharmacokinetic parameters were all analyzed using DAS 2.0 software (China Pharmaceutical University).

\section{Results and Discussion}

Method Optimization. At present, most of the extracts of the genus Uncaria reported in the literature use the alkaline ethyl acetate liquid-liquid extraction method. In this paper, acetonitrile protein-precipitation method, perchloric acid protein-precipitation method, ethyl acetate liquid-liquid extraction method, and solid-phase extraction method were investigated. The recovery rate of the alkaloid extraction method was compared with the recovery rates of alkaloids extracted by different methods. It is unstable, and the operation is time-consuming; the solid-phase extraction method is costly; the perchloric acid method is incomplete in addition to protein. Therefore, the acetonitrile proteinprecipitation method was chosen as a pretreatment method for samples. The optimization of the extract of target resulted in an acceptable sensitivity and matrix effect [24-28]. As for the complication of the rat plasma samples, the addition of $200 \mu \mathrm{L}$ acetonitrile could meet the requirements of removing the proteins and other potential interferences out of $50 \mu \mathrm{L}$ plasma samples.

Liquid chromatography conditions separate isocorynoxeine from the endogenous interfering substances as much as possible from the analyte retention time [29-34]. In the investigation of chromatographic conditions, mobile phase systems such as methanol-water, acetonitrile-water, methanol- $0.1 \%$ formic acid, and acetonitrile- $0.1 \%$ formic acid were investigated. The results of using acetonitrile- $0.1 \%$ formic acid system were suitable. It can effectively separate the isocorynoxeine and other substances, and the endogenous substances have no interference, and meet the requirements of blood concentration analysis.

Method Validation. Figure 2 illustrates the UPLC-MS/MS chromatograms of blank plasma samples spiked with isocorynoxeine. There were no endogenous substances that had intervened in the detection of isocorynoxeine, suggesting the selectivity of the method was acceptable. 

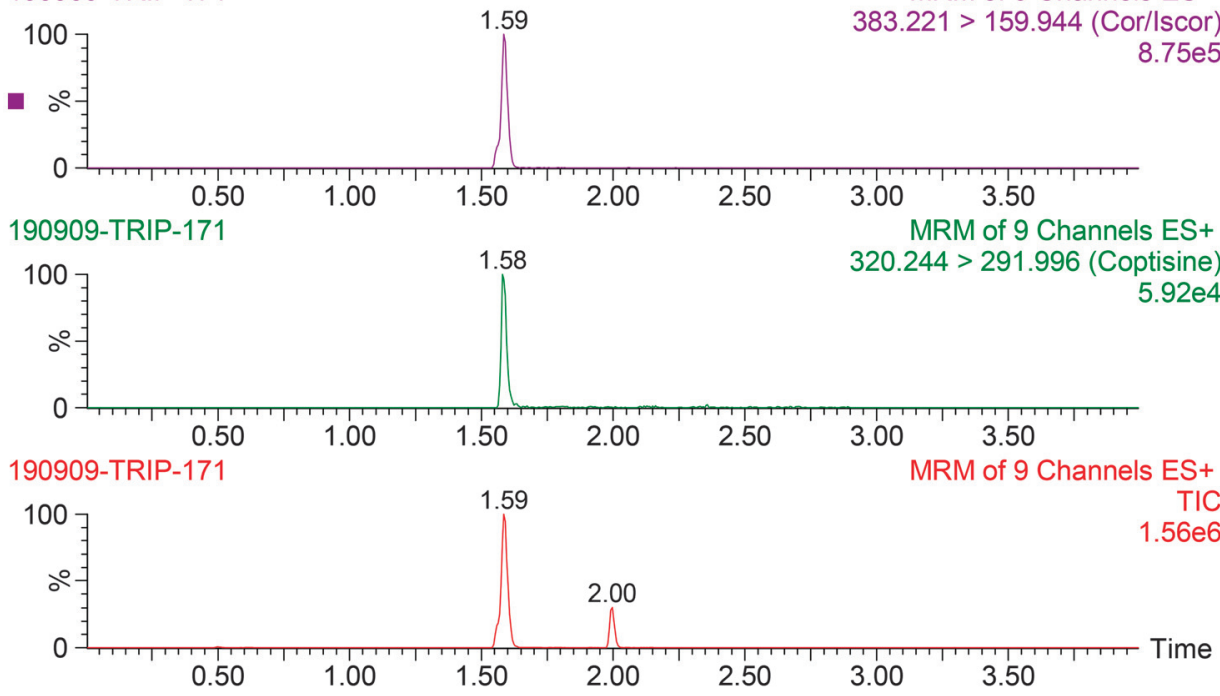

Figure 2. Representative UPLC-MS/MS of isocorynoxeine and the IS in rat plasma

Table 1. Accuracy, precision, matrix effect, and recovery of isocorynoxeine in rat plasma $(n=6)$

\begin{tabular}{lrrrrrrr}
\hline $\begin{array}{l}\text { Concentration } \\
(\mathrm{ng} / \mathrm{mL})\end{array}$ & \multicolumn{2}{c}{$\begin{array}{c}\text { Accuracy } \\
(\%)\end{array}$} & & \multicolumn{2}{c}{$\begin{array}{c}\text { Precision } \\
(\% \mathrm{NSD})\end{array}$} & $\begin{array}{c}\text { Matrix Effect } \\
(\%)\end{array}$ & $\begin{array}{c}\text { Recovery } \\
(\%)\end{array}$ \\
\cline { 2 - 3 } & $\begin{array}{c}\text { Intra- } \\
\text { day }\end{array}$ & $\begin{array}{c}\text { Inter- } \\
\text { day }\end{array}$ & & $\begin{array}{c}\text { Intra- } \\
\text { day }\end{array}$ & $\begin{array}{c}\text { Inter- } \\
\text { day }\end{array}$ & & \\
\hline 1 & 102.3 & 93.8 & & 10.3 & 11.8 & $93.1 \pm 7.5$ & $87.7 \pm 6.7$ \\
50 & 95.5 & 106.2 & & 9.1 & 10.7 & $99.5 \pm 8.3$ & $78.9 \pm 4.3$ \\
900 & 86.2 & 98.7 & & 8.5 & 8.2 & $94.7 \pm 5.3$ & $81.4 \pm 5.6$ \\
1800 & 97.0 & 110.4 & & 4.9 & 10.6 & $89.1 \pm 4.7$ & $87.7 \pm 6.2$ \\
\hline
\end{tabular}

The concentration of isocorynoxeine standard curve in rat plasma was within the range of $1-2000 \mathrm{ng} / \mathrm{mL}$. The LLOQ of isocorynoxeine in rat plasma was $1 \mathrm{ng} / \mathrm{mL}$. The standard curve equation of isocorynoxeine in the rat plasma was $Y=0.0199 C+0.0201, r=0.9964$, where $Y$ represents the peak area ratio of the isocorynoxeine to the IS, and $C$ represents the concentration of isocorynoxeine in rat plasma.

The intra-day and inter-day precisions (\%RSD) of isocorynoxeine in rat plasma were lower than $12 \%$. The accuracy range was between $86.2 \%$ and $110.4 \%$, the matrix effect was between $89.1 \%$ and $99.5 \%$, and the recovery was higher than $78.9 \%$ (Table 1).
The rat plasma at room temperature for $2 \mathrm{~h}$, at $-20{ }^{\circ} \mathrm{C}$ for 30 days, and under the freeze-thaw stability test, the variation of isocorynoxeine was within $\pm 14 \%$, and the RSD was less than $12 \%$, which indicated that the stability of isocorynoxeine was acceptable.

Pharmacokinetics. The plasma samples from 6 male rats following a single i.p. dose of $15 \mathrm{mg} / \mathrm{kg}$ isocorynoxeine were analyzed by using the validated UPLC-MS/MS method. The mean plasma concentration-time curves for isocorynoxeine are shown in Figure 3. The main pharmacokinetic parameters analyzed using the non-compartment model are listed in Table 2. The $t_{1 / 2}$ of isocorynoxeine is $4.9 \pm 2.1 \mathrm{~h}$, which

Table 2. Main pharmacokinetic parameters of isocorynoxeine in rats after intraperitoneal $(15 \mathrm{mg} / \mathrm{kg})$ administration $(n=6)$

\begin{tabular}{lcc}
\hline Parameters & Unit & i.p. $15 \mathrm{mg} / \mathrm{kg}$ \\
\hline $\mathrm{AUC}_{(0-t)}$ & $\mathrm{ng} / \mathrm{mL} * \mathrm{~h}$ & $857.1 \pm 426.5$ \\
$\mathrm{AUC}_{(0-\infty)}$ & $\mathrm{ng} / \mathrm{mL}$ h & $858.6 \pm 425.7$ \\
$\mathrm{MRT}_{(0-t)}$ & $\mathrm{h}$ & $0.8 \pm 0.2$ \\
$\mathrm{MRT}_{(0-\infty)}$ & $\mathrm{h}$ & $0.9 \pm 0.2$ \\
$t_{1 / 2 z}$ & $\mathrm{~h}$ & $4.9 \pm 2.1$ \\
$\mathrm{Vz}$ & $\mathrm{L} / \mathrm{kg}$ & $159.0 \pm 109.3$ \\
$\mathrm{CLz}$ & $\mathrm{L} / \mathrm{h} / \mathrm{kg}$ & $20.9 \pm 9.0$ \\
$C_{\max }$ & $\mathrm{ng} / \mathrm{mL}$ & $1022.3 \pm 455.7$ \\
\hline
\end{tabular}

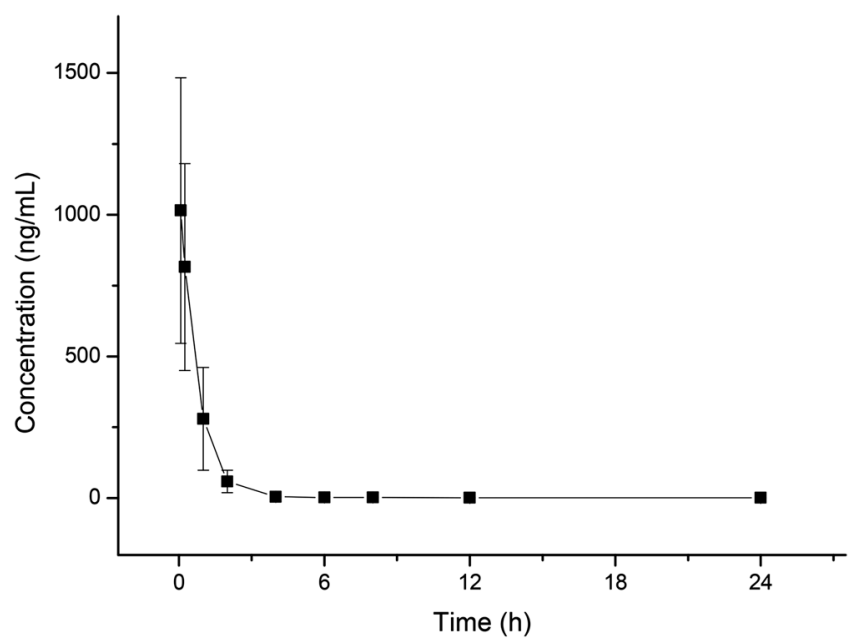

Figure 3. Plasma concentration-time curve of isocorynoxeine after intraperitoneal $(15 \mathrm{mg} / \mathrm{kg})$ administration $(n=6)$ 
indicates quick elimination, while it was reported that the elimination $t_{1 / 2}$ was estimated to be $1.05 \mathrm{~h}$ after oral administration [18].

\section{Conclusion}

In summary, we first report the pharmacokinetic properties of major isocorynoxeine metabolites by i.p. administration in vivo. A UPLC-MS/MS method was developed for the rapid determination of the pharmacokinetic properties of isocorynoxeine in rat plasma for i.p. administration at $15 \mathrm{mg} / \mathrm{kg}$. The linear range was $1-2000 \mathrm{ng} / \mathrm{mL}$, and $50 \mu \mathrm{L}$ plasma was used and processed by the acetonitrile precipitation method. This method was applied in pharmacokinetics of isocorynoxeine in rats. Our study provides helpful information about the pharmacokinetic properties of tetracyclic oxindole alkaloids.

Acknowledgments. This work was supported by Wenzhou Science and Technology Bureau (Y20180816), the second batch of agricultural cooperatives in Yinzhou District in 2018 (NO. 23), and the youth fund of Jinhua Central Hospital (JY2016-2-07).

\section{Reference}

1. Ndagijimana, A.; Wang, X.; Pan, G.; Zhang, F.; Feng, H.; Olaleye, O. Fitoterapia 2013, 86, 35-47.

2. Wang, Y. L.; Dong, P. P.; Liang, J. H.; Li, N.; Sun, C. P.; Tian, X. G.; Huo, X. K.; Zhang, B. J.; Ma, X. C.; Lv, C. Z. Phytomedicine 2018, 51, 120-127. 3. Zhu, S.; Li, Q.; Chen, S.; Wang, Y.; Zhou, L.; Zeng, C.; Dong, J. Pharm. Biol. 2018, 56, 548-558.

4. Feng, Z.; Hou, J.; Yu, Y.; Wu, W.; Deng, Y.; Wang, X.; Zhi, H.; Zhang, L.; Wu, W.; Guo, D. A. Front. Pharmacol. 2019, 10, 845

5. Geng, C. A.; Yang, T. H.; Huang, X. Y.; Ma, Y. B.; Zhang, X. M.; Chen, J. J. J. Ethnopharmacol. 2019, 232, 39-46.

6. Liu, A.; Chu, Y. J.; Wang, X.; Yu, R.; Jiang, H.; Li, Y.; Zhou, H.; Gong, L. L.; Yang, W. Q.; Ju, J. J. Evidence-Based Complementary Altern. Med. 2018, 2018, 9281946.

7. Lopes, A. A.; Chioca, B.; Musquiari, B.; Crevelin, E. J.; Franca, S. C.; Fernandes da Silva, M., and Pereira, A.M.S. Sci. Rep. 2019, 9, 11349.

8. Navarro, M.; Arnaez, E.; Moreira, I.; Hurtado, A.; Monge, D.; Monagas, M. Antioxidants 2019, 8 .

9. Navarro-Hoyos, M.; Alvarado-Corella, D.; Moreira-Gonzalez, I.; Arnaez-Serrano, E.; Monagas-Juan, M. Antioxidants 2018, 7.

10. Santo, G. D.; Grotto, A.; Boligon, A. A.; Da Costa, B.; Rambo, C L.; Fantini, E. A.; Sauer, E.; Lazzarotto, L. M. V.; Bertoncello, K. T.; Junior,
O. T.; Garcia, S. C.; Siebel, A. M.; Rosemberg, D. B.; Magro, J. D.; Conterato, G. M. M., and Zanatta, L. Environ. Sci. Pollut. Res. 2018, 25, 11703-11715

11. Guo, Q.; Yang, H.; Liu, X.; Si, X.; Liang, H.; Tu, P.; Zhang, Q. Fitoterapia 2018, 127, 47-55.

12. Wei, X.; Jiang, L. P.; Guo, Y.; Khan, A.; Liu, Y. P.; Yu, H. F.; Wang, B.; Ding, C. F.; Zhu, P. F.; Chen, Y. Y.; Zhao, Y. L.; Chen, Y. B.; Wang, Y. F.; Luo, X. D. Nat. Prod. Bioprospect. 2017, 7, 413-419.

13. Pan, H.; Yang, W.; Yao, C.; Shen, Y.; Zhang, Y.; Shi, X.; Yao, S.; Wu, W.; Guo, D. J. Chromatogr. A 2017, 1516, 102-113.

14. Huang, B. Y.; Zeng, Y.; Li, Y. J.; Huang, X. J.; Hu, N.; Yao, N.; Chen, M. F.; Yang, Z. G.; Chen, Z. S.; Zhang, D. M.; Zeng, C. Q. Int. J. Oncol. 2017, 51, 257-268.

15. Li, L.; Xu, L.; Chen, M.; Zhang, G.; Zhang, H.; Chen, A. J. Pharm. Biomed. Anal. 2017, 141, 39-45.

16. Li, T.; Xu, K.; He, J.; Jahan, N.; Song, J.; Wang, S. Toxicol. Appl. Pharmacol. 2019, 376, 95-106.

17. Li, T.; Xu, K.; Che, D.; Huang, Z.; Jahan, N.; Wang, S. NaunynSchmiedeberg's Arch. Pharmacol. 2018, 391, 1285-1293.

18. Zhao, L.; Zang, B.; Qi, W.; Chen, F.; Wang, H.; Kano, Y.; Yuan, D. Fitoterapia 2016, 111, 49-57.

19. Zhao, L.; Qi, W.; Chen, F.; Sun, J.; Yuan, D. Eur. J. Drug Metab. Pharmacokinet. 2016, 41, 615-626.

20. Wang, W.; Li, B.; Chen, Y. P.; Li, M. H.; Hattori, M. J. Liq. Chromatogr. Relat. Technol. 2016, 39, 77-86.

21. Cai, J. Z.; Lin, C. L.; Hu, L. F.; Lin, G. Y.; Wang, X. Q.; Ma, J. S. J.

Liq. Chromatogr. Relat. Technol. 2013, 36, 2232-2241.

22. Zimmer, D. Bioanalysis 2014, 6, 13-19.

23. FDA Guidance for Industry Analytical Procedures and Methods Validation for Drugs and Biologics 2014, https://www.fdanews.com/ext/ resources/files/02/02-19-14-Guidance.pdf.

24. Chen, R.; Lu, M.; Tu, X.; Sun, W.; Ye, W.; Ma, J.; Wen, C.; Wang, X.; Geng, P. Acta Chromatogr. 2019, 31, 146-150.

25. Han, A.; Lin, G.; Cai, J.; Wu, Q.; Geng, P.; Ma, J.; Wang, X.; Lin, C. Acta Chromatogr. 2019, 31, 99-104.

26. Song, H.; Huang, Y.; Zhu, D.; Tong, S.; Zhang, M.; Wang, X.; Bao, X. Curr. Pharm. Anal. 2019, 15, 194-199.

27. Wang, S.; Lin, Z.; Su, K.; Zhang, J.; Zhang, L.; Gao, Z.; Wang, Z.; Ma, J.; Wang, X. Acta Chromatogr. 2018, 30, 26-30.

28. Ye, W.; Sun, W.; Chen, R.; Wang, Z.; Cui, X.; Zhang, H.; Qian, S.; Zheng, Q.; Zhou, Y.; Wan, J.; Xu, J.; Wang, X.; Zhou, Y. Acta Chromatogr 2019, 31, 120-125.

29. Chen, L.; You, W.; Chen, D.; Cai, Y.; Wang, X.; Wen, C.; Wu, B. BioMed Res. Int. 2018, 2018, 6562309.

30. Chen, L.; Zhang, B.; Liu, J.; Fan, Z.; Weng, Z.; Geng, P.; Wang, X.; Lin, G. BioMed Res. Int. 2018, 2018, 1578643.

31. Geng, P. W.; Luo, J.; Weng, Z. W.; Fan, Z. H.; Zhang, B.; Ma, J. S.; Wang, X. Q.; Zhang, M. L. Biomed. Chromatogr. 2018, 32, E4273.

32. Li, T.; Ye, W.; Huang, B.; Lu, X.; Chen, X.; Lin, Y.; Wen, C.; Wang,

X. J. Pharm. Biomed. Anal. 2019, 168, 133-137.

33. Geng, P.; Luo, X.; Peng, X.; Lin, Z.; Chen, W.; Zhang, J.; Wen, C.; Hu, L.; Hu, S. Acta Chromatogr. 2018, 30, 231-235.

34. Geng, P.; Zhang, J.; Chen, B.; Wang, Q.; Wang, S.; Wen, C. Acta Chromatogr. 2018, 30, 136-140. 